\title{
HUBUNGAN MOTIVASI TERHADAP KUALITAS MUTU LULUSAN SISWA SEKOLAH DASAR NEGERI (SDN) 1 SOLEAR TANGERANG (Study Kasus Pada Siswa Berlatar Belakang Anak Pedagang)
}

\author{
Endang Iryani \\ Program Studi Pendidikan Bahasa Inggris Universitas MH Thamrin \\ E-mail: endang1084@gmail.com
}

\begin{abstract}
Abstrak
Penelitian ini pertama-tama bertujuan untuk mengetahui peranan strategi memotivasi siswa belajar dalam meningkatkan kualitas tamatan pada Sekolah Dasar Negeri (SDN) 1 Solear Tangerang, dengan study kasus pada siswa yang berasal dari keluarga pedagang. Masyarakat kecamatan Solear hampir 90\% berprofesi sebagai pedangang pasar, sehingga anak mereka hanya bertemu dengan orang tua mereka di saat sore hari sampai dengan pagi hari. Hipotesis yang diuji adalah : Terdapat peranan strategi memotivasi siswa belajar dalam meningkatkan kualitas tamatan pada Sekolah Dasar Negeri (SDN) 1 Solear Tangerang pada siswa anak pedagang. Metode penelitian adalah kuantatif, dengan pendekatan survei. Sampel berjumlah 38 orang guru yang diperoleh melalui acak dari populasi guru pada Sekolah Dasar Negeri (SDN) 1 Solear Tangerang. Data dikumpulkan dengan angket dan dianalisis dengan teknik mediasi menggunakan regresi ganda. Simpulan : 1) Nilai koefisien korelasi (R) variabel strategi memotivasi siswa belajar (X) sebesar 0.729, hal ini menunjukkan bahwa koefisien korelasi variabel strategi memotivasi siswa belajar mempunyai tingkat hubungan yang kuat, karena berada pada interval koefisien 0.60 - 0.799. Dengan demikian bahwa variabel bebas strategi memotivasi siswa belajar menunjukkan hubungan atau korelasi yang kuat dan searah dengan variabel terikat kualitas tamatan. Nilai koefisien determinasi atau $R$ Square sebesar 0.531. Hal ini menunjukkan 53,1 \% variabel kualitas tamatan $(Y)$ ditentukan oleh faktor variabel strategi memotivasi siswa belajar (X), sedangkan sisanya 46,9 \% ditentukan faktor-faktor lain. 2) Dari hasil perhitungan diperoleh nilai $t_{\text {hitung }}=6.385>$ $t_{\text {tabel }}$ 1,684, maka Ho ditolak dan Hi diterima. Atau dengan kata lain bahwa terdapat hubungan yang signifikan antara strategi memotivasi siswa belajar dengan kualitas tamatan pada Sekolah Dasar Negeri (SDN) 1 Solear Tangerang.
\end{abstract}

Kata kunci: motivasi, mutu siswa

\section{PENDAHULUAN}

Lembaga pendidikan adalah sebagai satu sistem yang dikelilingi oleh lingkungannya yang terdiri dari bermacam-macam sistem yang semuanya disebut suprasistem. Sistem tertenun dalam suprasistem mengadakan kaitan secara erat dan rapi, saling memberi dan saling menerima. Perkembangan ekonomi menentukan kemamkmuran bangsa dan masyarakat. Pendidikan ikut ambil bagian dalam mengembangkan keterampilan tenaga-tenaganya baik keterampilan berpikir maupun keterampilan tangan. Para perencana perlu memperhatikan perkembangan dan kondisi ekonomi daerah tempatnya berada. Tenaga jenis mana yang dibutuhkan, keterampilan apa yang perlu disiapkan agar cocok dengan keadaan ekonomi tersebut adalah merupakan tugas perencanaan partisipatori dalam pendidikan. 
Cita-cita bangsa dan semangat kebangsaan serta cara-cara untuk mencapai citacita itu sebagai ideologi adalah merupakan faktor politik yang perlu diperhatikan oleh para perencana pendidikan. Sebab cita-cita bangsa dan semangat kebangsaan paling intensif dikembangkan melalui pendidikan semenjak masa sekolah. Perkembangan segi ini pada setiap individu berjalan perlahan-lahan bersamaan dengan perkembangan segisegi lain melalui pendidikan, sampai pada waktunya kelak menjadi warga negara yang tangguh membela dan memperjuangkannya cita-cita bangsanya.

Perencanaan partisipatori memperhatikan cita-cita seperti ini dan berusaha merealisasi dalam lembaga pendidikan. Karena itu para perencana perlu memikirkan pada bagian kegiatan pendidikan yang mana hal itu dimasukkan, bagaimana metodenya dan siapa saja yang patut dilibatkan. Para perencana pendidikan juga perlu memperhatikan demografi yaitu kependudukan antara lain kepadatan penduduk didaerahnya, penyebarannya dan besarnya jumlah warga yang pantas masuk sekolah. Kondisi-kondisi itu perlu mendapat perhatian oleh para perencana. Seperti masyarakat Kecamatan Solear kabupaten Tangerang, yang notaben masyarakatnya adalah pedangang di pasar tradisional Cisoka. Keseharian masyarakat pedagang adalah mereka berangkat pukul 5.30 WIB pagi dan pulang dari pasar adalah pukul 17.30 WIB. sehingga mereka sampai rumah rata-rata pukul 18.30 WIB. Dengan kondisi kelelahan, mereka tidak pernah memperhatikan hasil anak-anak mereka belajar bahkan terkadang mereka malamnya harus belanja barang-barang yang akan mereka jual keesokan harinya. Hal ini menjadikan anak-anak mereka tidak diperhatikan dalam belajar. (hasil observasi peneliti).

Kondisi ini menjadikan guru yang ada disekolah harus mampu menciptakan suasana belajar yang mendukung akan keadaan siswa anak dari para pedagang tersebut. Sebab, kepekaan pengajar terhadap lingkungan masyarakat juga menjadi tanggung jawab dalam mengaplikasikan tujuan bangsa yakni mencerdaskan kehidupan bangsa. Peningkatan kualitas pendidikan bukanlah tugas yang ringan karena tidak hanya berkaitan dengan permasalahan teknis, tetapi mencakup berbagai persoalan yang sangat rumit dan kompleks, baik yang menyangkut perencanaan, pendanaan maupun efisiensi dan efektivitas penyelenggaraan sistem sekolah. Peningkatan kualitas pendidikan juga menuntut manajemen pendidikan yang lebih baik. Sayangnya, selama ini aspek manajemen pendidikan pada berbagai tingkat dan satuan pendidikan belum mendapat 
perhatian yang serius sehingga seluruh komponen sistem pendidikan kurang berfungsi dengan baik. Lemahnya manajemen pendidikan juga memberikan dampak terhadap efisiensi internal pendidikan yang terlihat dari jumlah peserta didik yang mengulang kelas dan putus sekolah.

\section{TINJAUAN PUSTAKA}

\section{Motivasi}

Motivasi berasal dari kata motif. Motif berarti suatu perangsang atau dorongan dari dalam (inner drive) yang menyebabkan seseorang membuat sesuatu. Payaman J. Simanjuntak (2001:199) mengatakan bahwa, motivasi dalam sekolah merupakan proses bagaimana menumbuhkan dan menimbulkan dorongan supaya seseorang berbuat atau belajar. Oleh sebab itu setiap guru akan selalu mengusahakan agar kegiatan yang dilakukan untuk mencapai tujuan yang telah ditetapkan dapat dilakukan dengan cara yang efektif dan efisien. Untuk itu perlu diadakan perencanaan, pengorganisasian, koordinasi kerja dan pengawasan secara baik. Dengan kata lain hal-hal itu semua dilaksanakan agar tujuan yang telah ditetapkan dapat dicapai secara efektif dan efisien.

Dengan jalan memotivasi para siswa dapat diharapkan semangat dan kegairahan belajar dapat ditingkatkan untuk mendorong agar para siswa belajar lebih semangat dan lebih bergairah, maka cara-cara yang dilakukan adalah dengan jalan melaksanakan motivasi pada siswa. Dengan demikian motivasi adalah usaha atau kegiatan dari guru sekolah untuk menimbulkan dan meningkatkan semangat dan kegairahan belajar dari para siswanya.

Secara sederhana dapat dibedakan dua bentuk motivasi siswa. Kedua bentuk tersebut adalah sebagai berikut :

\section{Motivasi Intrinsik}

Motivasi ini adalah pendorong belajar siswa yang bersumber dari dalam diri siswa sebagai individu, berupa kesadaran mengenai pentingnya atau manfaat pelajaran yang dilaksanakannya. Dengan kata lain motivasi ini bersumber dari pelajaran yang dikerjakan, baik karena mampu memenuhi kebutuhan atau menyenangkan atau memungkinkan mencapai suatu tujuan, maupun karena memberikan harapan tertentu yang positif dimasa depan. 


\section{Motivasi Ekstrinsik}

Motivasi ini adalah pendorong belajar yang bersumber dari luar diri siswa sebagai individu, berupa suatu kondisi mengharuskannya melaksanakan pelajarannya secara maksimal. Misalnya berdedikasi tinggi dalam belajar karena penilaian hasil belajar, prestasi belajar atau memiliki kemampuan yang besar, pujian, hukuman dan lain-lain.

Dalam rangka memotivasi para siswa, setidak-tidaknya terdapat 3 tanggungjawab utama seorang guru. Ketiga tanggung jawab ini adalah :

1. Merumuskan batasan pelaksanaan pelajaran siswanya.

Dalam rumusan tersebut harus jelas jenis/jumlah (kuantitatif) dan bobot (kualitatif) tugas-tugas yang menjadi tanggungjawab setiap siswanya.

2. Menyediakan dan melengkapi fasilitas untuk pelaksanaan belajar siswa, agar bagi siswa yang memiliki motivasi belajar yang tinggi tidak menjadi hambatan untuk melaksanakannya secara maksimal.

3. Memilih dan melaksanakan cara terbaik dalam mendorong atau memotivasi pelaksanaan belajar para siswanya.

\section{Mutu lulusan/siswa}

Definisi kualitas menurut Vincent Gasperz (2003 : 181), adalah “Totalitas dari karakteristik atau produk (barang dan jasa) yang menunjang kemampuannya untuk memenuhi kebutuhan yang dispesifikasikan”. Menurut Taliziduhu Ndraha (2005:12), sumber daya manusia yang berkualitas tinggi adalah sumber daya manusia yang mampu menciptakan bukan saja nilai kompetitif generatif-inovatif dengan menggunakan energi tertinggi seperti Intellegence, Creativity dan Imagination, tidak lagi semata-mata menggunakan energi kasar seperti bahan mentah, lahan, air, tenaga, otot, dan sebagainya.

Menurut Collin Coulson-Thomas dalam Eri Krisna (2001 : 8), bahwa kualitas yang dimiliki oleh siswa dalam sekolah masa depan antara:

a. Mampu memberikan dorongan serta perhatian yang khusus tentang visi, sasaran tujuan organisasi yang jelas difokuskan pada siswa.

b. Memiliki sikap yang sesuai dengan nilai sekolah yang dapat mempengaruhi keputusan dan prospek pribadinya. 
c. Adanya komitmen secara terbuka mengenai pemberdayaan yang mengikutsertakan siswa, adanya saling percaya dan saling memperhatikan pengembangan jati diri dalam proses peningkatan dari melalui belajar yang terus menerus.

d. Sikap dan mampu untuk bekerja dan belajar dengan efektif dalam sebuah tim pada waktu yang bersamaan.

e. Menghadapi sikap yang baik dalam menghadapi rintangan dan cobaan yang timbul.

f. Sikap yang baik dari siswa yang mampu menghadapi rintangan yang timbul sangat diperlukan untuk memperoleh kesanggupan bertahan tehadap segala macam ujian, penderitaan dan tantangan baik jasmaniah maupun rohaniah.

Pemerintah juga berkewajiban untuk membangun standar seperti kurikulum dan evaluasi hasil belajar, standar kelembangaan, standar ketenagaan, dan pendidikan yang bermutu. Masyarakat atas dukungan moral, pemikiran dan bantuan dana yang diberikannya mendapatkan pendidikan yang bermutu bagi anak-anaknya yang ditandai dengan kemampuannya bersaing.

Pendidikan didesain untuk mampu mengatasi krisis multidimensional dengan membuat neraca lama, masa sekarang dan masa yang akan dating. Sekolah membutuhkan bantuan yang luas dari masyarakat dan sebaliknya, masyarakat memerlukan pendidikan bagi anak-anaknya. Mereka saling membutuhkan sehingga kekuatan dan keterbatasan masing-masing bisa saling melengkapi menjadi sebuah kekuatan efektif manajemen sekolah. Secara konsepsional, impliksi otonomi pemerintah daerah adalah meningkatkan performansi (kinerja) sekolah karena diberikan ruang pemberdayaan yang memadai untuk mencapai tujuan pendidikan nasional yang bermutu melalui pemberdayaan masyarakat. UU No. 25 Tahun 1999 tentang perimbangan keuangan pusat dan daerah dimaksudkan untuk menentukan pola hubungan kewenangan antara pusat dan daerah, provinsi dan kabupaten/kota dan unit pemerintahan dibawahnya dengan prinsip desentralisasi.

\section{METODE}

Penelitian ini peneliti menggunakan metode survey dengan paradigma study asosiasi dan memanfaatkan analisis data kuantitatif. Populasi penelitian sebanyak 62 orang. Sampel dalam penelitian ini adalah guru-guru pada Sekolah Dasar Negeri (SDN) 1 Solear Tangerang sebanyak 38 orang. Untuk menentukan besarnya sampel dapat 
digunakan model rumus dari Slovin (Azhari, 2002 : 53). Pada penenelitian ini peneliti menggunakan error sebanyak $10 \%$.

Untuk memperoleh data yang lengkap dalam obyek penelitian ini, maka penulis menggunakan 2 (dua) cara dalam teknik pengumpulan data yang digunakan dalam penelitian ini, yaitu Penelitian Kepustakaan dan Penelitian Lapangan. Penelitian lapangan penulis maksudkan untuk memperoleh data primer dan data sekunder, metode yang ditempuh dengan metode kuesioner. teknik analisis data yang digunakan adalah analisa Koefisien Korelasi Sederhana, Analisis Koefisien Determinasi

\section{HASIL DAN PEMBAHASAN PENELITIAN}

\section{Variabel Strategi Memotivasi Siswa Belajar (X)}

Setelah dilakukan perhitungan terhadap jawaban yang diberikan oleh 38 orang yang menjadi sampel penelitian, maka rangkuman data variabel strategi memotivasi siswa belajar sebagai salah satu faktor yang berperan dalam meningkatkan kualitas tamatan pada Sekolah Dasar Negeri (SDN) 1 Solear Tangerang dapat dilihat pada tabel dibawah ini :

Tabel 1. Data Statistik Variabel Strategi Memotivasi Siswa Belajar (X)

\begin{tabular}{lll}
\hline & & $\mathrm{X}$ \\
\hline $\mathrm{N}$ & Valid & 38 \\
\cline { 2 - 3 } & Missing & 0 \\
\hline Mean & 62,3684 \\
\hline Std. Error of Mean &, 72687 \\
\hline Median & $62,6667^{\mathrm{a}}$ \\
\hline Mode & $60,00^{\mathrm{b}}$ \\
\hline Std. Deviation & 4,48072 \\
\hline Variance & 20,077 \\
\hline Skewness &,- 567 \\
\hline Std. Error of Skewness &, 383 \\
\hline Kurtosis &, 646 \\
\hline Std. Error of Kurtosis &, 750 \\
\hline Range & 21,00 \\
\hline Minimum & 49,00 \\
\hline Maximum & 70,00 \\
\hline Sum & 2370,00 \\
\hline Percentiles & $59,5000^{\mathrm{c}}$ \\
& & 62,6667 \\
\hline & & 65,6667 \\
\cline { 2 - 3 } & 50 & \\
\cline { 2 - 3 } & 75 & $\mathbf{2 5}$ \\
\hline
\end{tabular}

a Calculated from grouped data.

b Multiple modes exist. The smallest value is shown

c Percentiles are calculated from grouped data.

Sumber : Spss vers 13.0 
Berdasarkan hasil pengumpulan data melalui kuesioner, variabel strategi memotivasi siswa belajar (X) sebagai salah satu faktor yang berperan dalam meningkatkan kualitas tamatan pada Sekolah Dasar Negeri (SDN) 1 Solear Tangerang.

\section{Variabel Kualitas Tamatan (Y)}

Setelah dilakukan perhitungan terhadap jawaban yang diberikan oleh 38 orang yang menjadi sampel penelitian, maka rangkuman data variabel kualitas tamatan pada Sekolah Dasar Negeri (SDN) 1 Solear Tangerang dapat dilihat pada tabel dibawah ini :

Tabel 2. Data Statistik Variabel Kualitas Tamatan (Y)

\begin{tabular}{|c|c|c|}
\hline & & $\mathrm{Y}$ \\
\hline \multirow[t]{2}{*}{$\mathrm{N}$} & Valid & 38 \\
\hline & Missing & 0 \\
\hline Mean & & 63,9211 \\
\hline Std. Error of Mean & & 67403 \\
\hline Median & & $63,8571^{\mathrm{a}}$ \\
\hline Mode & & 69,00 \\
\hline Std. Deviation & & 4,15498 \\
\hline Variance & & 17,264 \\
\hline Skewness & &,- 390 \\
\hline Std. Error of Skewness & & ,383 \\
\hline Kurtosis & &,- 665 \\
\hline Std. Error of Kurtosis & &, 750 \\
\hline Range & & 15,00 \\
\hline Minimum & & 55,00 \\
\hline Maximum & & 70,00 \\
\hline Sum & & 2429,00 \\
\hline \multirow[t]{3}{*}{ Percentiles } & 25 & $61,0000^{\mathrm{c}}$ \\
\hline & 50 & 63,8571 \\
\hline & 75 & 67,8333 \\
\hline
\end{tabular}

\footnotetext{
a Calculated from grouped data.

b Multiple modes exist.

c Percentiles are calculated from grouped data.

Sumber : Spss vers 20.0
}

Berdasarkan hasil pengumpulan data melalui kuesioner variabel kualitas lulusan pada Sekolah Dasar Negeri (SDN) 1 Solear Tangerang.

\section{Pengujian Hipotesis}

Penulis akan melakukan analisis terhadap satu variabel bebas yang berhubungan dengan satu variabel terikat. Variabel bebas tersebut adalah strategi memotivasi siswa belajar (X), sedangkan variabel terikatnya adalah kualitas tamatan (Y). Hasil print 
output komputer dengan program SPSS 22.0 for Windows diperoleh hasil persamaan sebagai berikut :

Tabel 3. Koefisien Korelasi Sederhana

Correlations

\begin{tabular}{|lr|r|r|}
\hline & & \multicolumn{1}{|c|}{$Y$} & \multicolumn{1}{|c|}{ X } \\
\hline Pearson Correlation & $Y$ & 1,000 &, 729 \\
& $X$ &, 729 & 1,000 \\
\hline Sig.(1-tailed) & $Y$ & - &, 000 \\
& $X$ &, 000 &. \\
\hline$N$ & $Y$ & 38 & 38 \\
& $X$ & 38 & 38 \\
\hline
\end{tabular}

Tabel 4. Pedoman Untuk Memberikan Interpretasi Koefisien Korelasi

\begin{tabular}{cc}
\hline Interval Koefisien & Tingkat Hubungan \\
\hline $0.00-0.199$ & Sangat rendah \\
$0.20-0.399$ & Rendah \\
$0.40-0.599$ & Sedang \\
$0.60-0.799$ & Kuat \\
$0.80-1.000$ & Sangat kuat \\
\hline
\end{tabular}

Sumber : Sugiyono, 2002:183

Berdasarkan tabel 3 di atas, nilai koefisien korelasi (R) variabel strategi memotivasi siswa belajar (X) sebesar 0.729, hal ini menunjukkan bahwa koefisien korelasi variabel strategi memotivasi siswa belajar mempunyai tingkat hubungan yang kuat, karena berada pada interval koefisien $0.60-0.799$. Dengan demikian bahwa variabel bebas strategi memotivasi siswa belajar menunjukkan hubungan atau korelasi yang kuat dan searah dengan variabel terikat kualitas tamatan.

Untuk mengetahui pengaruh variabel $\mathrm{X}$ terhadap variabel $\mathrm{Y}$, dapat digunakan analisis Koefisien Determinasi $(\mathrm{Kd})$ yaitu sebagai berikut :

$$
\begin{aligned}
\mathrm{Kd} & =\mathrm{r}^{2} \times 100 \% \\
& =(0.729)^{2} \times 100 \% \\
& =0.531 \times 100 \% \\
& =53,1 \%
\end{aligned}
$$

Berdasarkan perhitungan di atas, nilai koefisien determinasi atau $R$ Square sebesar 0.531. Hal ini menunjukkan 53,1\% variabel kualitas tamatan (Y) ditentukan oleh faktor variabel strategi memotivasi siswa belajar (X), sedangkan sisanya 46,9\% ditentukan faktor-faktor lain, yang dalam penelitian ini tidak dapat diteliti oleh peneliti. 
Untuk mengetahui kebenaran dari perhitungan koefisien korelasi di atas, maka diperlukan pengujian hipotesis. Perumusan hipotesis yang akan diuji diberi simbol $\mathrm{H}_{\mathrm{o}}$, sedangkan untuk hipotesis alternatif diberi simbol $\mathrm{H}_{\mathrm{a}}$.

Perhitungan test observasi $\left(\mathrm{t}_{\mathrm{o}}\right)$ dapat dicari dengan menggunakan rumus sebagai berikut:

$$
\begin{aligned}
t_{\text {hitung }} & =\frac{r \sqrt{n-2}}{\sqrt{1-r^{2}}} \\
t_{\text {hitung }} & =6.385
\end{aligned}
$$

Berdasarkan hasil $t_{\text {hitung }}$ tersebut selanjutnya dibandingan dengan $t_{\text {tabel }}$.

$\mathrm{t}_{\text {tabel }}$ dengan $\alpha 0,025 \%$ dengan $\mathrm{n}=38$

$\mathrm{t}_{\text {tabel }} \alpha=1.684$

Dari hasil perhitungan di atas diperoleh nilai $t_{\text {hitung }}=6.385>t_{\text {tabel }} 1.684$, maka Ho ditolak dan Ha diterima. Atau dengan kata lain bahwa terdapat hubungan yang signifikan antara strategi memotivasi siswa belajar dalam meningkatkan kualitas tamatan pada Sekolah Dasar Negeri (SDN) 1 Solear Tangerang.

\section{SIMPULAN}

Berdasarkan hasil pengujian dari hipotesis di atas, ternyata semua hipotesis dapat diterima dan bersifat signifikan. Hal ini dapat dilihat dalam pembahasan di bawah ini:

1. Hubungan Strategi Memotivasi Siswa Belajar Dalam Meningkatkan Kualitas Tamatan. Nilai koefisien korelasi (R) sebesar 0,729, hal ini menunjukkan bahwa koefisien korelasi variabel strategi memotivasi siswa belajar dalam meningkatkan kualitas tamatan mempunyai tingkat hubungan yang kuat, karena berada pada interval koefisien 0,60 - 0,799. Dengan demikian bahwa variabel bebas strategi memotivasi siswa belajar menunjukkan hubungan atau korelasi yang kuat dan searah dengan variabel kualitas tamatan pada Sekolah Dasar Negeri (SDN) 1 Solear Tangerang.

2. Dari hasil perhitungan diperoleh nilai $t_{\text {hitung }}$ sebesar 6,385 , sedangkan $t_{\text {tabel }}$ dengan $\alpha$ $0,025 \%$ diperoleh $t_{\text {tabel }}$ sebesar 1,684. Dengan demikian $t_{\text {hitung }}>t_{\text {tabel }}$, maka Ho ditolak dan Ha diterima. Hal ini berarti bahwa terdapat hubungan yang positif dan signifikan strategi memotivasi siswa belajar dalam meningkatkan kualitas tamatan pada Sekolah Dasar Negeri (SDN) 1 Solear Tangerang. 
Research and Development Journal Of Education

Vol. 4 No. 2 April 2018

ISSN 2406-9744

\section{DAFTAR PUSTAKA}

Collin, Coulson, dalam Eri Krisna. 2001. Kualitas Kerja. The Dryden Press New York.

Dessler, Gary. 2003. Manajemen Personalia. Erlangga, Jakarta.

Gasperz, Vincent. 2003. Manajemen Kualitas : Penerapan Konsep-konsep Kualitas Dalam Manajemen Bisnis Total, Yayasan Indonesia Emas. Jakarta: Gramedia Pustaka Utama.

Hadari Nawawi, 2003, Manajemen Sumber Daya Manusia, Cetakan Kelima, Gadjah Mada University Press, Yogyakarta.

Kartono, Kartini, 2004, Psikologi Sosial untuk Manajemen, Jakarta : Raja Grafindo Persada.

Mohammad As'ad, 2003, Psikologi Industri, Edisi Revisi, Yogyakarta, Liberty.

Simanjuntak, Payaman, J., 2001, Manajemen Sumberdaya Manusia, Program Pascasarjana, Unkris, Jakarta.

Sugiyono. 2002. Methode Penelitian Administrasi. Cetakan ke 8. Bandung: Alfabeta

Talizhidu Ndraha. 2005. Manajemen Sumber Daya Manusia. Jakarta: Erlangga. 